\title{
マルチレートサンプリングシステムのモデル追従適応制御*
}

\author{
石 飛 光 章*1, 西岡 義 洋*2, 木下 博*2
}

\section{Model Following Adaptive Control of Multirate Sampling Systems}

\author{
Mitsuaki ISHITOBI*3, Yoshihiro NISHIOKA and Hiroshi KINOSHITA \\ ${ }^{* 3}$ Department of Mechanical Engineering and Materials Science, Kumamoto University, \\ 2-39-1 Kurokami, Kumamoto-shi, Kumamoto, 860-8555 Japan
}

\begin{abstract}
This paper deals with model following adaptive control of linear time-invariant systems with two sampling rates: a slower one for the output and a faster one for the input. It is known that intersample ripples often arise in the outputs of the closed-loop multirate sampling systems although multirate control has interesting advantages. In this paper, a ripple-suppressed multirate model following control scheme is presented. A state observer is designed at the output sampling instants and a filter is constructed at the input sampling instants in order to estimate the output at the intersample instants of the outputs. Next, an adaptive version of the algorithm for systems with unknown parameters is shown. Experimental results applied to a position servo system with a supersonic sensor are given to indicate the effectiveness.
\end{abstract}

Key Words : Digital Control, Computer Control, Supersonic Wave, Multirate Sampling Systems, Model Following Control

\section{1. 緒覀}

離散時間制御系設計方法の多くは, 入力と出力との サンプリンク周期が等しい系を対象としている. とこ ろが, 制御対象によっては, センサのサイクルタイム の制約上, 入力の望ましいサンプリング周期ほど, 出 カサンプリング周期を短くできない場合がある. たと えば, プロセス制御においてセンサとしてカスクロマ トグラフを用いるときには, このような状況にしばし ば遭遇し，機械システムの制御でも視覚センサや超音 波センサを使用するときは同様である.

このような場合に入カのサンプリング周期を出力 のサンプリング周期より短くする制御方法が, マルチ レートサンプリング制御 ${ }^{(1)}(2)$ と呼ばれて研究が行わ れている. 中には, 2 自由度制御系の立場から取り組 んだ研究 ${ }^{(3)}$ もあるが, 多くは周期時変コントローラ やリフティング手法コントローラと呼ばれる制御系設 計の枠組みに入る研究である. 周期時変コントローラ やリフティング手法コントローラをもつフィードバッ ク系では, 出カサンプリンク間にリップルが生じるこ とが指摘されている(4) (5). そこで, リップルを抑制す る方法が検討されている. Tangirala $ら^{(5)}$ は, 内部モ

* 原稿受付 2003 年 6 月 9 日.

*1 正員, 熊本大学工学部 ( 860 -8555 熊本市黒髪 2-39-1).

$* 2$ 熊本大学大学院自然科学研究科.

E-mail : mishi@ kumamoto-u.ac.jp
デル原理を利用する方法を提案しているが, この方法 では適用可能な規範出力がステップ信号などに限定さ れる.これに対し, 制御対象を入カサンプリング周期 でモデリングする方法が考察されている(6) (7). この 方法では, 入カサンプリング時点での出力をいかにし て推定するかがポイントである.これまでの方法は, 大部分の不安定系には適用できない.

本研究では, 入力のサンプリング周期でモテリリング する方法にもとづくが, 不安定な制御対象にも適用可 能な方法を示す. 入力サンプリング時刻における出力 値を推定するために, 従来の方法では出力誤差法を基 本とする出力推定器を構成するのに対し, 本研究の方 法では, 出カサンプリング時刻において状態観測器を, また, 入力サンプリング時刻においてはフィルタを構 成する点にこれまでとの違いがある. 本論文では, 初 めにパラメータ值が既知の場合の設計方法を示し, つ ぎに正確なパラメータ值が未知の場合のパラメータ推 定機構を含む方法を与えている. さらに, 超音波セン サを有する位置サーボ実験システムに, 提案する制御 手法を適用し, 実際に適用可能であることを実証する. 従来のマルチレートサンプリング制御の研究の多くは, 実用システムや実験システムでの実証を行っておらず, 実際的な適用可能性の検討は残されたままである. 


\section{2. 問題の設 定}

制御対象は, 入出力をそれぞれ $u(t), y(t)$ とする次 式の一入出力離散時間系であるとする.

$$
A_{1}\left(q^{-1}\right) y(t)=q^{-d} B_{1}\left(q^{-1}\right) u(t)
$$

ここに, サンプリング周期は $T$ であり, $q^{-1}$ は時間遅 れ演算子を表し, $d$ はむだ時間である. また, $A_{1}\left(q^{-1}\right)$, $B_{1}\left(q^{-1}\right)$ は

$$
\begin{aligned}
& A_{1}\left(q^{-1}\right)=1+a_{11} q^{-1}+\cdots+a_{1 n} q^{-n} \\
&=\left(1-\alpha_{1} q^{-1}\right) \cdots\left(1-\alpha_{n} q^{-1}\right) \\
& B_{1}\left(q^{-1}\right)=b_{10}+b_{11} q^{-1}+\cdots+b_{1 m} q^{-m} \\
& b_{10} \neq 0
\end{aligned}
$$

と表されるものとする. また, つぎの仮定が成立して いるものとする.

1) システム (1) は最小実現である.

2) システム (1) は最小位相系である. すなわち, $B_{1}\left(q^{-1}\right)$ は渐近安定である.

3) 出力は $J$ (2 以上の整数) 回に 1 回測定可能.

問題は, 出力 $y(t)$ が規範モデルの出力 $y_{r}(t)$ に漸近 的に一致する制御系を設計することである. 出力值が $J T$ ごとに測定されるにもかかわらず, 出カサンプリ ング時刻だけでなく, 入カサンプリング時刻において も制御誤差をなくすことによって, 多くのマルチレー トサンプリング制御で指摘されている, リップル発生 問題を回避する.

モデル追従制御では，一般的に，規範モデルを陽に 記述し，制御入力を規範モデル入力によって与えるが, ここでは，規範出力によって与えるようにしている. これは規範モテルを陽に記述せず, 直接規範モデル出 力を与える場合にも対応できるようにするためであり， 前者の形式にあわせることも可能である.

つぎに，モテル (1) 式を入手可能な信号のみによる 動特性式に変換しておく.

(1) 式の両辺に

$$
C\left(q^{-1}\right)=\prod_{i=1}^{n}\left(1+\alpha_{i} q^{-1}+\cdots+\alpha_{i}^{J-1} q^{1-J}\right)
$$

を乗じると，等価な非最小実現形式

$$
A\left(q^{-J}\right) y(t)=q^{-d} B\left(q^{-1}\right) u(t)
$$

が得られる.ここに

$$
\begin{aligned}
A\left(q^{-J}\right) & =A_{1}\left(q^{-1}\right) C\left(q^{-1}\right) \\
& =1+a_{1} q^{-J}+\cdots+a_{n} q^{-n J} \\
B\left(q^{-1}\right) & =B_{1}\left(q^{-1}\right) C\left(q^{-1}\right) \\
& =b_{0}+\cdots+b_{m+n J-n} q^{-m-n J+n}
\end{aligned}
$$

である.

\section{3. 制 御 系 設 計}

制御系設計におけるキーポイントは, 入カサンプリ ング時刻における出力推定值の構成方法である.ここ では, 出カサンプリング時刻において状態観測器を設 計し, 入カサンプリング時刻においてはフィルタを設 計することによって, 出力推定值を構成できることを 示す.

i) 出カサンプリンク時刻 $(t=J, 2 J, \cdots)$ における状 態推定

制御対象 (1) 式は $n$ 次ベクトル $\boldsymbol{x}(t)$ を用いた状態 方程式で

$$
\begin{cases}\boldsymbol{x}(t+1) & =\Phi \boldsymbol{x}(t)+\psi u(t) \\ y(t) & =\boldsymbol{c}^{T} \boldsymbol{x}(t)\end{cases}
$$

と表すことができる. 入力のサンプリンク周期が $T$ で あるのに対し, 出力のサンプリング周期は $J T$ である ことから，Jステップことの状態の関係を表す方程式 は, 上式を $J-1$ 回繰り返すことにより

$$
\left\{\begin{array}{c}
x(t)=\Phi^{J} x(t-J)+\psi u(t-1) \\
+\Phi \psi u(t-2)+\cdots \\
+\Phi^{J-1} \psi u(t-J) \\
y(t)=c^{T} x(t)
\end{array}\right.
$$

となる.ここで, $\Phi^{J}$ の特性多項式は (6) 式に一致す る. そこで, 正則変換 $z(t)=H_{0} x(t)$ によって (9) 式 を可観測標準形に変換し, $\widehat{\boldsymbol{z}}(t), \widehat{\boldsymbol{x}}(t)$ をそれぞれ $\boldsymbol{z}(t)$, $\boldsymbol{x}(t)$ の推定值として, 状態観測器

$$
\begin{aligned}
\widehat{\boldsymbol{z}}(t)= & F \widehat{\boldsymbol{z}}(t-J)+\boldsymbol{g} y(t-J) \\
& +\boldsymbol{\psi}_{1} u(t-1)+\cdots+\psi_{J} u(t-J) \\
F= & {\left[\begin{array}{cccc}
-f_{1} & 1 & \cdots & 0 \\
\vdots & \ddots & \ddots & 1 \\
-f_{n} & 0 & \cdots & 0
\end{array}\right] } \\
\boldsymbol{g}= & {\left[\begin{array}{c}
f_{1}-a_{1} \\
\vdots \\
f_{n}-a_{n}
\end{array}\right] } \\
\boldsymbol{\psi}_{k}= & H_{0} \Phi^{k-1} \psi, k=1, \cdots, J
\end{aligned}
$$

を構成する. ここで, $F$ は安定な行列を与える. した がって, 状態変数の推定值は

$$
\widehat{\boldsymbol{x}}(t)=H_{0}^{-1} \widehat{\boldsymbol{z}}(t)
$$

によって得られる.

ii) 出カサンプリング時刻間の入カサンプリング時刻 $(t \neq 0, J, 2 J, \cdots(t$ が $J$ で割り切れない整数である ことを意味する)）における出力推定 
まず，以下の状態フィルタを構成する.

$$
\left\{\begin{array}{cc}
\overline{\boldsymbol{x}}(t)= & \Phi \widehat{\boldsymbol{x}}(t-1)+\psi u(t-1) \\
& t=J+1,2 J+1, \cdots \\
\overline{\boldsymbol{x}}(t)= & \Phi \overline{\boldsymbol{x}}(t-1)+\psi u(t-1) \\
& t \neq J+1,2 J+1, \cdots
\end{array}\right.
$$

これらのフィルタを用いて, 出力推定値を

$$
\widehat{y}(t)=c^{T} \bar{x}(t), t \neq 0, J, 2 J, \cdots
$$

\section{と構成する.}

入力は以下の手順で構成する. まず, 漸近安定な多 項式

$$
\begin{gathered}
A_{r}\left(q^{-1}\right)=1+d_{11} q^{-1} \cdots+d_{1 h} q^{-h}, \\
h \leq n+d-1
\end{gathered}
$$

を与える. つぎに, 多項式 $R\left(q^{-1}\right)$ と $S\left(q^{-1}\right)$ を方程式

$$
A_{r}\left(q^{-1}\right)=A_{1}\left(q^{-1}\right) R\left(q^{-1}\right)+q^{-d} S\left(q^{-1}\right)
$$

により求める. ここで

$$
\begin{aligned}
& R\left(q^{-1}\right)=1+r_{1} q^{-1}+\cdots+r_{d-1} q^{-d+1} \\
& S\left(q^{-1}\right)=s_{0}+s_{1} q^{-1}+\cdots+s_{n-1} q^{-n+1}
\end{aligned}
$$

である.これより, 入力は次式で与える.

$$
\begin{aligned}
u(t)= & \frac{1}{b_{10}}\left[A_{r}\left(q^{-1}\right) y_{r}(t+d)\right. \\
& -S\left(q^{-1}\right) \widetilde{y}(t)-\left\{B_{1}\left(q^{-1}\right) R\left(q^{-1}\right)\right. \\
& \left.\left.-b_{10}\right\} u(t)\right]
\end{aligned}
$$

ここに

$$
\widetilde{y}(t)= \begin{cases}y(t) & t=0, J, 2 J, \cdots \\ \widehat{y}(t) & t \neq 0, J, 2 J, \cdots\end{cases}
$$

以下で, 制御目的の達成について説明する.

制御入力の構成方法からわかるように, 出力サンプ リング時点間の入カサンプリング時刻における出力推 定值 $\widehat{y}(t)$ が真の出力 $y(t)$ に渐近すれば, 入出力サン プリング周期が等しいシングルレート方式によるモデ ル追従制御系構成に一致するので, 制御目的の達成, すなわち

$$
y_{r}(t)-y(t) \rightarrow 0
$$

が成立し ${ }^{(8)}$, 出力サンプリング時刻だけでなく, 入力 サンプリング時刻においても制御対象出力が規範出力 に渐近することは明らかである. したがって，入力サ ンプリング時刻における出力推定值 $\widehat{y}(t)$ の収束性に ついて以下で述べる.
まず, 状態観測器より, 出カサンプリング時刻にお いて

$$
\widehat{\boldsymbol{x}}(i J) \rightarrow \boldsymbol{x}(i J), i \rightarrow \infty
$$

となる. つぎに, フィルタと出力推定式より

$$
\begin{array}{r}
y(i J+k)-\widehat{y}(i J+k)=c^{T} \Phi^{k}(x(i J)-\widehat{x}(i J)), \\
k=1,2, \cdots, J-1
\end{array}
$$

が成り立つこと, (21) 式が成立すること, さらに, $k$ が $J-1$ 以下の正整数であることから, $i$ の増加とと もに, 上式右辺は 0 に収束し, すべての $k$ について, 出力推定誤差も漸隇する.

つぎに安定性について論じる. 上で述べているよう に，(21)，(22) 式より $\widehat{y}(t)$ が $y(t)$ に漸近する. した がって, (15), (1), (18) 式より

$$
\begin{aligned}
& A_{r}\left(q^{-1}\right) y(t+d) \\
& \quad=\left\{A_{1}\left(q^{-1}\right) R\left(q^{-1}\right)+q^{-d} S\left(q^{-1}\right)\right\} y(t+d) \\
& \quad=B_{1}\left(q^{-1}\right) R\left(q^{-1}\right) u(t)+S\left(q^{-1}\right) y(t) \\
& \quad=A_{r}\left(q^{-1}\right) y_{r}(t+d) \\
& A_{r}\left(q^{-1}\right) B_{1}\left(q^{-1}\right) u(t) \\
& \quad=A_{r}\left(q^{-1}\right) A_{1}\left(q^{-1}\right) y(t+d) \\
& \quad=A_{r}\left(q^{-1}\right) A_{1}\left(q^{-1}\right) y_{r}(t+d)
\end{aligned}
$$

となり, $A_{r}\left(q^{-1}\right), B_{1}\left(q^{-1}\right)$ が安定であることから， $y(t), u(t)$ はいずれも有界となる.

最後に, パラメータ変動に対するロバスト性につい て述べる. 本論文の設計方法では, 状態観測器を (9) 式に対して構成する. したがって, もとの (8) 式にパ ラメー夕誤差が存在し, たとえば $\Phi$ がパラメータ誤 差 $\Phi_{\Delta}$ を有しているとすれば, (9) 式の $\Phi^{J}$ がもつパ ラメー夕誤差は概略 $J \Phi_{\Delta}$ となる. つまり，(9) 式に関 するパラメー夕誤差は (8) 式のパラメー夕誤差のほぼ $J$ 倍に拡大し, 悪影響を受けやすくなる可能性がある. そこでそのひとつの対策として, 次章で述べる適応制 御が有効と考えられる.

\section{4. 適応制御系設計}

前章では, 事前に制御对象の正確なパラメータ值が わかっているとの前提で設計方法を与えている. ここ ではパラメータの正確な值が不明の場合の, パラメー 夕推定機構を含む適応制御系 ${ }^{(9)}$ の設計について述べる.

まず，入手可能な入出力データによる表現式 (5)に もとづいて, 非最小実現のパラメータを推定する. す なわち (5) 式を

$$
y(t)=\phi(t-1)^{T} \boldsymbol{\theta}
$$


と表現しなおしておく.ここに

$$
\begin{aligned}
\phi(t-1)^{T}= & {[-y(t-J), \cdots,-y(t-n J), u(t-d),} \\
& \cdots, u(t-d-m-n J+n)] \\
\boldsymbol{\theta}^{T}= & {\left[a_{1}, \cdots, a_{n}, b_{0}, \cdots, b_{m+n J-n}\right] }
\end{aligned}
$$

そして, $\boldsymbol{\theta}$ の推定值 $\widehat{\boldsymbol{\theta}}(t)$ を

$$
\begin{aligned}
\widehat{\boldsymbol{\theta}}(t)^{T}= & {\left[\widehat{a}_{1}(t), \cdots, \widehat{a}_{n}(t),\right.} \\
& \left.\widehat{b}_{0}(t), \cdots, \widehat{b}_{m+n J-n}(t)\right]
\end{aligned}
$$

と定義し，たとえば，最小 2 乗アルゴリズム

$$
\begin{gathered}
\widehat{\boldsymbol{\theta}}(i J)=\widehat{\boldsymbol{\theta}}(i J-J) \\
+\frac{P(i J) \phi(i J-1)[y(i J)-\bar{y}(i J)]}{\lambda+\phi(i J-1)^{T} P(i J) \phi(i J-1)} \\
P^{-1}(i J+J)=\lambda P^{-1}(i J) \\
+\phi(i J-1) \phi(i J-1)^{T} \\
\bar{y}(i J)=\phi(i J-1)^{T} \widehat{\boldsymbol{\theta}}(i J-J) \\
0<\lambda \leq 1, P^{-1}(0)>0, \widehat{b}_{0}(0) \neq 0 \\
\widehat{\boldsymbol{\theta}}(i J+k)=\widehat{\boldsymbol{\theta}}(i J), \quad k=1, \cdots, J-1
\end{gathered}
$$

によってパラメータ推定を行う. パラメータ推定值は 出カサンプリング時点でのみ更新される.

つぎに, 最小実現モデル (1) 式のパラメータベクト ルおよびその推定ベクトルをそれぞれ

$$
\begin{array}{r}
\boldsymbol{\zeta}^{T}=\left[a_{11}, \cdots, a_{1 n}, b_{10}, \cdots, b_{1 m}\right] \\
\widehat{\boldsymbol{\zeta}}(t)^{T}=\left[\widehat{a}_{11}(t), \cdots, \widehat{a}_{1 n}(t),\right. \\
\left.\widehat{b}_{10}(t), \cdots, \widehat{b}_{1 m}(t)\right]
\end{array}
$$

と定めて, $\widehat{\boldsymbol{\zeta}}(t)$ を以下のように求める. すなわち, (6), (7) 式から明らかに

$$
A\left(q^{-J}\right) B_{1}\left(q^{-1}\right)=A_{1}\left(q^{-1}\right) B\left(q^{-1}\right)
$$

が成立することから

$$
\widehat{A}\left(t, q^{-J}\right) \widehat{B}_{1}\left(t, q^{-1}\right)=\widehat{A}_{1}\left(t, q^{-1}\right) \widehat{B}\left(t, q^{-1}\right)
$$

にもとづくと, 推定ベクトル $\widehat{\boldsymbol{\zeta}}(i J)$ は

$$
M(i J) \widehat{\boldsymbol{\zeta}}(i J)=\widehat{\boldsymbol{\eta}}(i J)
$$

と表すことができる. ここで

$M(i J)$

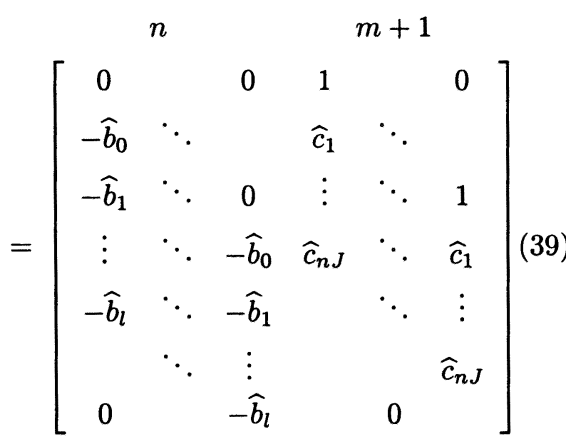

$$
l=m+n J-n
$$

$\widehat{c}_{j}(i J)$

$$
\begin{gathered}
= \begin{cases}\widehat{a}_{k}(i J), & j=k J, k=1, \cdots, n \\
0, & \text { その他 }\end{cases} \\
\widehat{\boldsymbol{\eta}(i J)^{T}=\left[\widehat{b}_{0}(i J), \cdots, \widehat{b}_{m+n J-n}(i J),\right.} \\
0, \cdots, 0]
\end{gathered}
$$

そして, $(m+n J+1) \times(m+n+1)$ 行列 $M(i J)$ は 正方ではないため, 擬似逆行列を用いて

$$
\widehat{\boldsymbol{\zeta}}(i J)=\left[M(i J)^{T} M(i J)\right]^{-1} M(i J)^{T} \widehat{\boldsymbol{\eta}}(i J)
$$

により, $\widehat{\boldsymbol{\zeta}}(t)$ を求める. $\widehat{\boldsymbol{\theta}}(t)$ と同様, 出カサンプリン グ時刻間の入カサンプリング時刻ではパラメータ更新 は行わない.すなおち

$$
\widehat{\boldsymbol{\zeta}}(i J+k)=\widehat{\boldsymbol{\zeta}}(i J), \quad k=1, \cdots, J-1
$$

以上により, 最小実現のパラメータ推定值が得られ るので, これを使って前章のアルゴリズムで制御系を 構成すればよい.

\section{5. 超音波センサを有する位置サーボ系の制御実験}

超音波センサは位置を非接触で計測できることや安 価であることを特徵とするが, 反面; 検出間隔が比較 的長いためマルチレート制御の適用を必要とする.

ここでは, 超音波センサを有する簡単な位置サーボ 系に, マルチレート制御を適用した結果を述べる.

実験に用いた位置サーボ系を図 1 に示す.

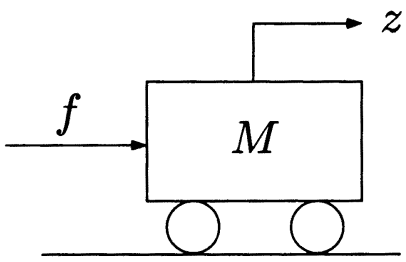

Fig. 1. Position servo system. 
マスの質量を $M[\mathrm{~kg}]$, マスの位置を $z[\mathrm{~m}]$, 粘性摩摖 係数を $\mu[\mathrm{Ns} / \mathrm{m}]$, 駆動力を $f[\mathrm{~N}]$, モータの電圧を $u[\mathrm{~V}]$ とする. モ一夕電圧と駆動力とは定数 $a$ により $f=a u$ なる関係式で表される. マスの位置 $z$ は超音波センサ で計測される.

このとき, 運動方程式は

$$
M \ddot{z}=a u-\mu \dot{z}
$$

と記述され, 入力をモー夕電圧, 出力をマスの位置と すると, 伝達関数は

$$
G(s)=\frac{K}{s\left(T_{1} s+1\right)}
$$

となる.ここで $K$ と $T_{1}$ は, それぞれ $a / \mu$ と $M / \mu$ で ある. 超音波センサの検出間隔に比較して, (45) 式の 時定数は小さく, 無視できる. また, 超音波センサは 時間遅れを有する. そこで, モー夕電圧と超音波セン サで計測される位置信号との伝達関数は次式のように 近似される.

$$
G(s)=\frac{K}{s} e^{-\tau s}
$$

伝達関数 $G(s)$ のパラメータ $K$ の概略値は $K=$ 0.135 であり, 出カサンプリング周期は超音波センサ の検出周期を考虑して $0.1[\mathrm{~s}]$ とした. また, 入力のサ ンプリング周期 $T$ は $0.02[\mathrm{~s}]$, すなわち, 入出カサン プリング周期比 $J$ を 5 とした. さらに, (46) 式のむ だ時間 $\tau$ は, ほほ $5 T=0.1[\mathrm{~s}]$ である.このとき, 離 散時間動特性は

$$
A_{1}\left(q^{-1}\right) y(t)=q^{-6} B_{1}\left(q^{-1}\right) u(t)
$$

と表される.ここに

$$
A_{1}\left(q^{-1}\right)=1-q^{-1}, \quad B_{1}\left(q^{-1}\right)=b_{10}
$$

である. パラメータの概略值は $b_{10}=0.00270$ である. 規範出力は

$$
\begin{gathered}
y_{r}(t)=\frac{1}{440}\left(13 \sin \left(\frac{2 \pi}{9.5} T t\right)+9 \sin \left(\frac{2 \pi}{14.5} T t\right)\right. \\
+18 \sin \left(\frac{2 \pi}{12.5} T t\right)+14 \sin \left(\frac{2 \pi}{13.5} T t\right) \\
\left.+20 \cos \left(\frac{2 \pi}{3.5} T t\right)-27 \cos \left(\frac{2 \pi}{18.5} T t\right)\right) \\
t=0,1,2, \cdots
\end{gathered}
$$

とした. パラメータ推定の動特性式 (25) は

$$
y(t)-y(t-5)=\phi(t-1) \theta
$$

と表される.ここに

$$
\begin{aligned}
\phi(t-1) & =u(t-6)+\cdots+u(t-10) \\
\theta & =b_{0}=b_{10}
\end{aligned}
$$

パラメータ $\theta$ の推定値は $\hat{\theta}(t)=\widehat{b}_{0}(t)$ である. パラ メータ推定値の初期值および設計パラメータは

$$
\begin{cases}\hat{\theta}(0)=0.00270, & \\ P(0)=1000, & \lambda=0.99 \\ A_{r}\left(q^{-1}\right)=1-0.6 q^{-1}, & f_{1}=-0.30\end{cases}
$$

と与えた. また, 出力の初期値および状態観測器とフィ ルタの初期值は 0 とした.

出力と規範出力を図 2 に示す. また, 入力と推定パ ラメータ $\widehat{b}_{0}(t)$ をそれぞれ図 3 と図 4 に示す. 規範出 カへの追従が達成されていることがわかる.

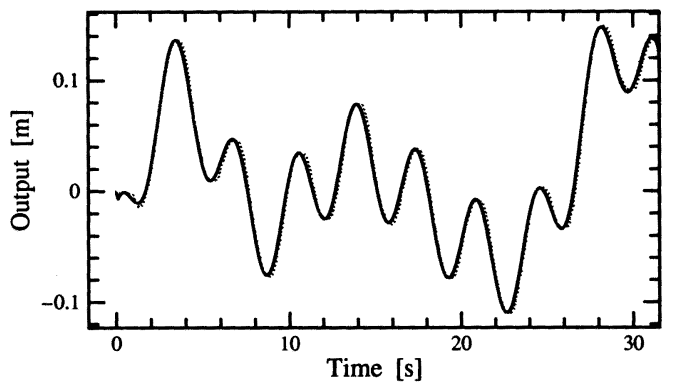

Fig. 2. The output comparison trajectories of adaptive control in experiment. Solid and dashed lines indicate plant and desired outputs, respectively.

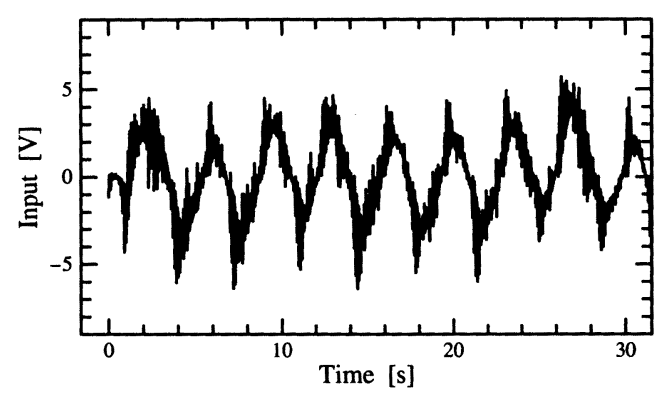

Fig. 3. The input trajectory. 


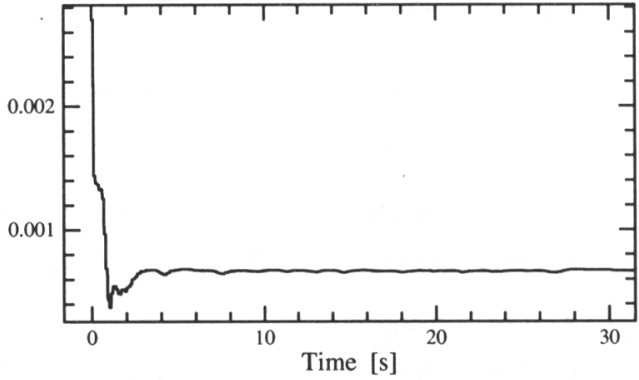

Fig. 4. The plant parameter trajectory, $\widehat{\theta}(\mathrm{t})$.

\section{6. 考 察}

$6 \cdot 1$ リップルの回避ここでは入力サンプリン グ時点における出力誤差が抑制されて, リップルの発 生問題が回避されることを前章の実験例を用いて述べ る. ただし，超音波センサの検出周期が $0.1[\mathrm{~s}]$ であり， 入力時点における出力を測定する実験はできないため, シミュレーションにより説明する.

従来のマルチレートサンプリング制御の例として, $N$-delay input control ${ }^{(4)}$ によるシミュレーションを 行った. その方法による, 入力サンプリング時点にお ける出力誤差を図 5 に示す. 本論文の方法の結果もあ わせて示している. 図からわかるように, 従来の方法 では, 出力サンプリング時刻においては出力誤差が現 れないが，その間の入力サンプリング時刻においては 出力誤差が現れる. 一方，本論文の方法では，すべて の入力サンプリング時刻において, 出力誤差が現れな くなっている.

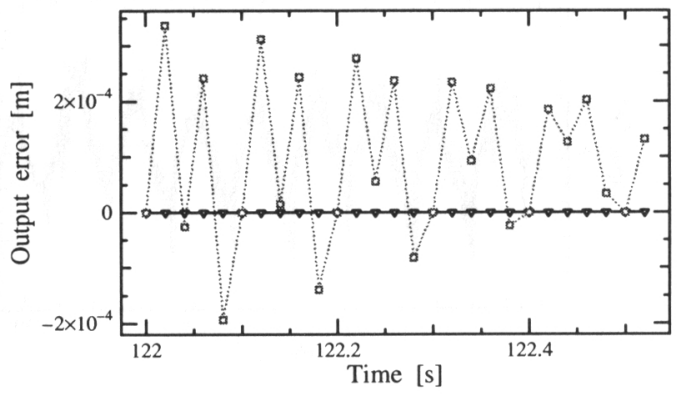

Fig. 5. The output error comparison trajectories in simulation. Solid and dashed lines indicate proposed control and $N$-delay input control errors, respectively.

6.2 非適応制御之の比較比較のために, パラ メー夕推定を行わない, すなわち非適応制御の実験結 果例を図 6 に示す.パラメー夕值の不正確さのため出
力追従が不完全である。

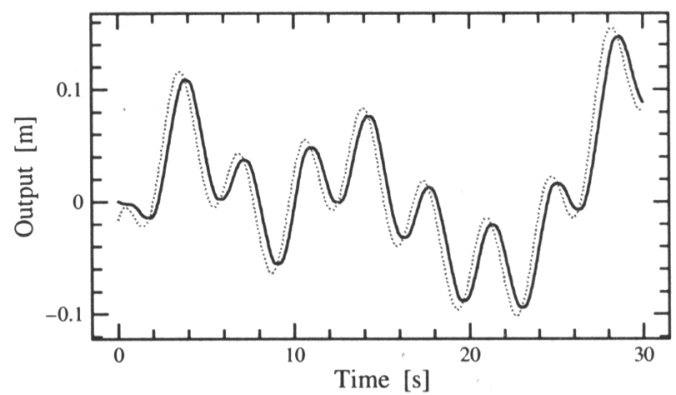

Fig. 6. The output comparison trajectories in experiment. Solid and dashed lines indicate plant and desired outputs, respectively.

6.3 シングルレート制御との比較＼cjkstart本論文のマ ルチレート制御では, 入力サンプリング時点において も出力追従が達成され, シングルレート制御に比べて 制御性能が向上することを, 前章の実験例を用いて述 ベる. 6.1 節で述べているように, 超音波センサの検出 周期が $0.1[\mathrm{~s}]$ であり, 入力時点における出力を測定す る実験はできないため, シミュレーションにより説明 する. 両方法で行ったシミュレーション結果の出力誤 差を図 7 に示す. 図からわかるように, シングルレー ト制御では, 出力サンプリング時刻においては出力誤 差が現れないが, その間では出力誤差が現れる. 一方, 本論文の方法では, すべての入力サンプリング時刻に おいて，出力追従が達成されている.

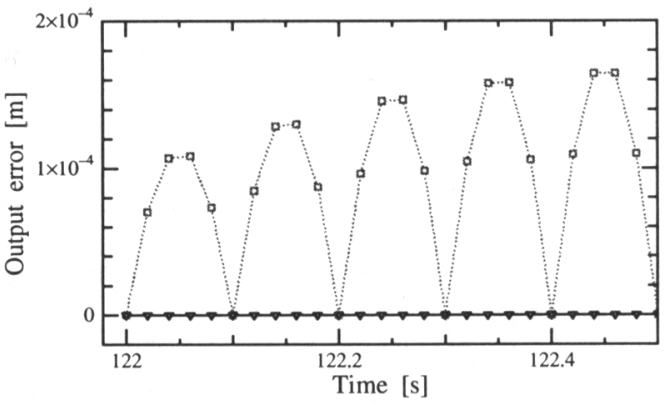

Fig. 7. The output error comparison trajectories in simulation. Solid and dashed lines indicate multirate and single rate control errors, respectively.

\section{7. 結 言}

本論文はマルチレートサンプリングシステムのモデ ル追従制御方法を与えた。この方法では，制御対象を 入力のサンプリング周期でモデリングして制御入力を 与えるため, リップル発生問題を回避できる.また, これまでの同種の方法に比べ，適用する際の制御対象 
に対する制約が少ない. パラメータが未知の場合の適 応制御系設計方法も示した. 最後に, 超音波センサを 有する位置サーボ実験システムに, 提案する制御手法 を適用し，有効性を明らかにした。

\section{謝辞}

実験に協力いただいた, 熊本大学大学院自然科学研 究科, 朱勤助手に謝意を表します.

$$
\text { 文献 }
$$

(1) Araki, M., and Yamamoto, K., Multivariable multirate sampled-data systems, state-space description, transfer characteristics and nyquist criterion, IEEE Trans. on Automat. Contr., 1986, AC-31-2, (1986), 145-154

(2) Al-Rahmani, H. M., and Franklin, G. F., Multirate control: A new approach, Automatica, 28-1, (1992), 35-44

（3）藤本博志・堀洋一・山口高司・中川真介, マルチレート サンプリングを用いた完全追従制御法による磁気ティ スク装置のシーク制御, 電気学会論文誌 D, 120-10, (2000), 1157-1164

(4) Moore, K. L., Bhattacharyya, S. P., and Dahleh, M., Capabilities and limitations of multirate control schemes, Automatica, 29-4, (1993), 941-951

(5) Tangirala, A. K., Li, D., Patwardhan, R. S., Shah, S. L. and Chen, T., Ripple-free conditions for lifted multirate control systems, Automatica, 37, (2001), 1637-1645

(6) Lu, W., Fisher, D. G., and Shah, S. L., Multirate constrained adaptive control, Int. J. Control, 51-6, (1990), 1439-1456

（7）石飛光章 - 河島英法, 出カサンプリング周期が長いシ ステムの離散時間 MRAC, システム制御情報学会論文 誌, 5-5, (1992), 207-209

(8) Goodwin, G. C., and Sin, K. S., Adaptive filtering, prediction and control, (1984), 118-177, PrenticeHall

(9) Ishitobi, M., Kawanaka, M., and Nishi, H., Ripplesuppressed multirate adaptive control, Preprints of 15th IFAC World Congress, (2002) 